

\title{
Aplicação de resíduos de frutas nativas da Mata Atlântica e Amazônia para a obtenção de confeitos drageados
}

\author{
Thaís A. Malavolta*, Kazumi K. Ramos, Priscilla Efraim
}

\begin{abstract}
Resumo
O Brasil apresenta papel de destaque na produção mundial de frutas, cujo processamento gera grande quantidade de resíduos. Estes subprodutos são ricos em fibras e compostos bioativos, com propriedades benéficas à saúde, sendo interessante sua aplicação em alimentos. Visando propor métodos para a aplicação e consumo direto dos subprodutos do processamento de polpa de frutas, o objetivo deste trabalho foi desenvolver núcleos a partir de resíduos do processamento de polpa de frutas nativas da Mata Atlântica, para a produção de confeitos drageados cobertos com cupulate (produto análogo ao chocolate e proveniente do cupuaçu, nativo da Amazônia). Os confeitos produzidos foram avaliados sensorialmente e quanto ao teor de compostos fenólicos totais (CFT) e foram comparados com núcleos idênticos cobertos com chocolate. Na avaliação sensorial, não houve diferença entre os drageados de uma mesma fruta produzidos com cupulate e chocolate, exceto para a uvaia, em que o chocolate foi preferido para os atributos de "sabor" e "impressão global". Dos confeitos produzidos, aquele com núcleo à base de uvaia drageado com chocolate foi o melhor avaliado. Com relação ao teor de CFT, observou-se que os drageados produzidos com cupulate apresentaram, em média, a metade do teor de CFT dos produzidos com chocolate.
\end{abstract}

\section{Palavras-chave:}

confeitos, subprodutos, frutas nativas

\section{Introdução}

O Brasil é um dos maiores produtores mundiais de frutas, incluindo espécies nativas. Muitas destas são desconhecidas por boa parte do público e apresentam características diferenciadas quanto à aparência e sabor, despertando interesse. Parte dessas frutas é utilizada na produção de polpa congelada, cujo processamento dá origem a uma grande quantidade de resíduos compostos por casca, bagaço, sementes ou caroços. Por possuírem fibras, compostos bioativos e minerais, é crescente o interesse na utilização destes em produtos destinados à alimentação humana. Um exemplo de produto é o estruturado de fruta elaborado a partir de resíduos (FONSECA et al., 2015). O cupulate é um produto similar ao chocolate, produzido a partir de amêndoas de cupuaçu. A cobertura de centros à base de resíduos de frutas com cupulate por meio do processo de drageamento pode melhorar sua aceitação sensorial e agregar valor ao produto.

Este trabalho teve como objetivo estabelecer uma metodologia para a produção de confeitos drageados cobertos com cupulate e centros a base de resíduos de três frutas nativas da Mata Atlântica: grumixama, uvaia e cambuci, os quais foram avaliados sensorialmente e quanto ao teor de antioxidantes. Os drageados cobertos com cupulate foram comparados com aqueles produzidos com chocolate.

\section{Resultados e discussão}

Os núcleos foram produzidos de acordo com Fonseca et al. (2015). O formato escolhido foi o cúbico pois aliou maior facilidade de produção e uniformidade no drageamento. Após o drageamento com chocolate e cupulate, foi realizada avaliação sensorial - teste de aceitação, 120 consumidores, escala estruturada variando de 1 (desgostei extremamente) até 9 (gostei extremamente) (STONE; SIDEL, 2004) - e determinação do teor de compostos fenólicos (HAMINIUK et al., 2011).
Para o drageamento, estabeleceu-se como padrão um aumento de massa de $250 \%$ pela adição de cobertura. Verificou-se que não houve diferença significativa nas médias obtidas para os drageados com cupulate e chocolate para os núcleos da mesma fruta, considerando-se todos os atributos sensoriais avaliados, com exceção da uvaia, para os atributos de "sabor" e "impressão global", para quais o chocolate foi 0 preferido.

Os confeitos cobertos com chocolate apresentaram maiores valores de compostos fenólicos totais. Houve diferença significativa entre todas as amostras, indicando que, além da diferença causada pela cobertura, as frutas possuem diferentes concentrações de compostos antioxidantes. Os teores de compostos fenólicos totais variaram entre 2,16 e 8,48 $\mathrm{mg}$ ácido gálico/g amostra seca (uvaia e cupulate e grumixama e chocolate).

\section{Conclusões}

Foi demonstrada a viabilidade tecnológica do uso de cupulate no processo de drageamento e de utilização de resíduos do processamento de frutas para a produção de núcleos para o drageamento. Os métodos empregados são simples, permitindo que pequenos produtores possam utilizá-los na agregação de valor de suas frutas. Além de apresentarem boas características antioxidantes, os confeitos desenvolvidos apresentaram boa aceitação pelos potenciais consumidores.

\section{Agradecimentos}

Ao CNPq; ao Sítio do Bello e CpKelco; à técnica do laboratório e aos colegas pela cooperação.

HAMINIUK, C.W.I. et al. Chemical, antioxidant and antibacterial study of Brazilian fruits. Int Journal of Food Sci and Tech, v.46, p. 1529-1537, 2011 STONE, H.; SIDEL, J. L. Sensory Evaluation Practices. 3rd ed. Amsterdam: Elsevier, 2004. 377 p.

FONSECA, L.H.S. et al. Use of the by-product of fruit pulp processing in the development of fruit leather. In: XXIII CONGRESSO PIBIC, 2015, Campinas. 